DOI: 10.12731/2070-7568-2019-2-72-82

УДК 338.2.24

\title{
ОСОБЕННОСТИ ОРГАНИЗАЦИИ ФИНАНСОВОГО МОНИТОРИНГА В РОССИИ
}

\author{
Сапожникова С.М., Рейхерт Н.В.
}

Статья посвящена актуальному вопросу - организации и осуществлению финансового мониторинга в России. В рамках борьбы государства по пресечению деятельности, связанной с отмыванием доходов, полученных преступным путем и финансирования терроризма в России создана трехуровневая система финансового мониторинга.

Цель работы. Рассмотреть систему осуществление финансового мониторинга в России и сформулировать предложения по улучшению ее деятельности.

Материалы и методы исследования. Эмпирическую базу исследования составили данные сайта Федеральной службы по финансовому мониторингу, актуальное законодательство в сфере финансового мониторинга, научные статьи. Методы исследования: аналитический, графический, статистический.

Авторами статьи даны конкретные предложения по улучшению организации финансового контроля в России.

Ключевые слова: финансовый мониторинг; надзорные органы; финансовые агенты; объекты надзора.

\section{FEATURES OF THE ORGANIZATION OF FINANCIAL MONITORING IN RUSSIA}

\section{Sapozhnikova S.M., Reichert N.V.}

The article is devoted to an urgent issue - the organization and implementation of financial monitoring in Russia. In the framework of the 
state's struggle to suppress activities related to the laundering of proceeds from crime and the financing of terrorism, a three-level financial monitoring system has been created in Russia.

Objective. Consider the system of financial monitoring in Russia and formulate proposals for improving its activities.

Materials and research methods. The empirical base of the study was the data from the website of the Federal Service for Financial Monitoring, current legislation in the field of financial monitoring, and scientific articles. Research methods: analytical, graphic, statistical.

The authors of the article made specific proposals for improving the organization of financial control in Russia.

Keywords: financial monitoring; supervisory authorities; financial agents; objects of supervision.

\section{Введение}

На сегодняшний день для финансового мониторинга, как науки, одним из основных вопросов является грамотное установление нормативных, финансовых и экономических критериев законного и незаконного качества проведения операции для того, чтобы объективно анализировать субъекты финансовых отношений, находящихся в группе тех, у которых имеются риски совершения легализации денежных средств и финансирования терроризма (ПОД/ФТ) [9, c. 184].

\section{Цель работы}

Рассмотреть систему осуществление финансового мониторинга в России и сформулировать предложения по улучшению ее деятельности.

\section{Материалы и методы исследования}

Эмпирическую базу исследования составили данные сайта Федеральной службы по финансовому мониторингу, актуальное законодательство в сфере финансового мониторинга, научные статьи. Методы исследования: аналитический, графический, статистический. 


\section{Результаты исследования и их обсуждение}

Под национальной безопасностью следует понимать такое состояние общества и государства, при котором обеспечивается развитие общества, достойное существование граждан и у государства существуют необходимые ресурсы, которые позволят отражать внутренние и внешние угрозы [6, с. 79]. Легализация доходов, полученных незаконным путем и финансирование терроризма в первую очередь посягают на благополучие и стабильность развития страны [5, с. 7].

В соответствии с Административным регламентом Росфиннадзор осуществляет контроль за выполнением юридическими и физическими лицами законодательства РФ о легализации доходов, полученных преступным путем и финансирования терроризма [2].

Отсюда финансовый мониторинг охватывает следующие основные направления:

1. предотвращение сделок посредством финансовых средств и имущества, приобретенных преступным путем, что обеспечивается с помощью создания норм и критериев внутреннего мониторинга агентами контроля,

2. выявление этих операций путем идентификации экономических субъектов, изучение их работы и взаимоотношений с контрагентами,

3. пресечение выявленных фактов путем приостановления функционирования агента и заморозку его счетов.

В РФ в соответствии с Федеральным законом № 115-Ф3 от 07.08.2001 сложилась трехуровневая структура финансового мониторинга [1].

Причем каждому уровню присущи свои специфические функции и полномочия, которые влияют на уровень отслеживаемых рисков. Рассмотрим организацию системы финансового мониторинга в РФ, представленную на рисунке 1 .

Как видно из рисунка 1 в РФ субъектами системы финансового мониторинга выступают те органы или организации, которые выполняют мониторинг и контроль за правомерностью движения денежных потоков в целях стабильности денежного обращения в стране. 
К первому уровню относится Росфинмониторинг, который осуществляет внешний контроль над всеми структурами системы, участвует в разработке и принятии нормативов и параметров контроля, также сбор и анализ полученных данных о подконтрольных сделках.

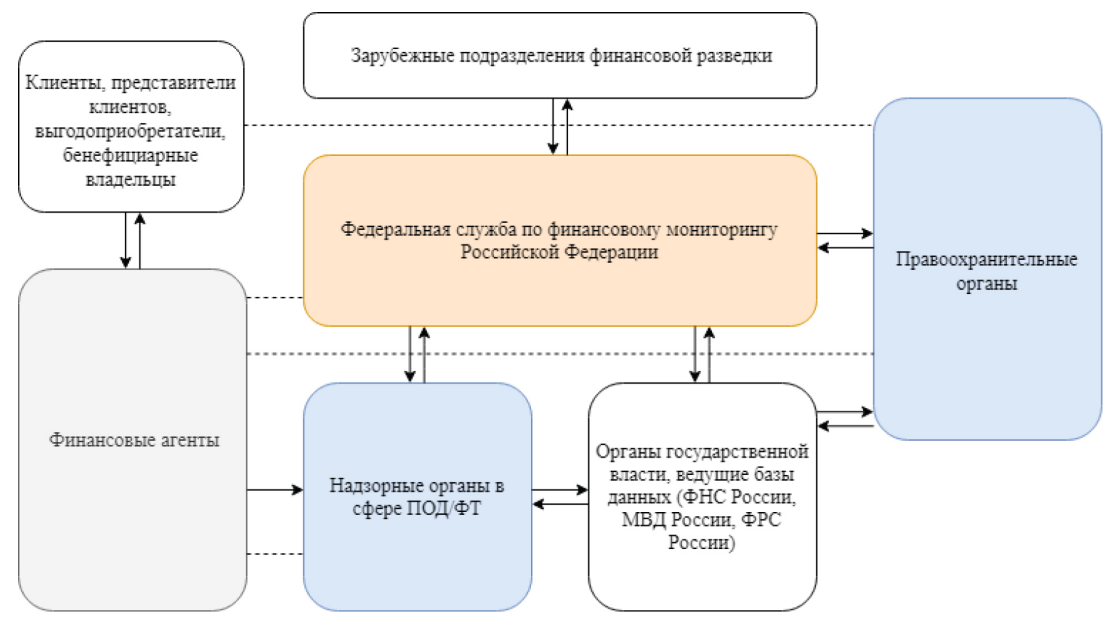

Рис. 1. Организация финансового мониторинга в РФ

Основными задачами Росфинмониторинга выступает организация работы, направленной на охрану интересов и законных прав граждан, общества и государства. Рассмотрим его цели, представленные на рисунке 2.

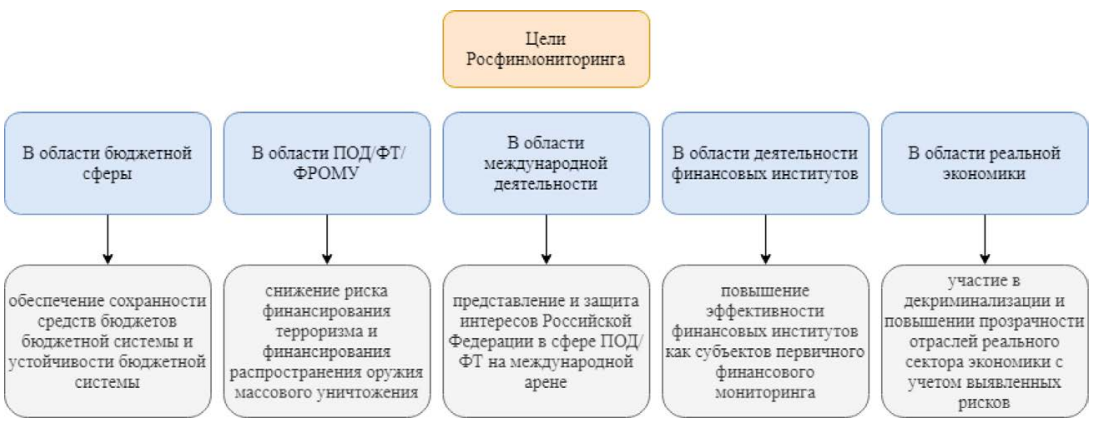

Рис. 2. Цели Росфинмониторинга 
Вторым уровнем данной системы в Российской Федерации выступают институты, надзирающие за деятельностью финансовых агентов.

Особенностью работы надзорных органов, которые представлены Банком России, а также «Российской государственной пробирной палатой при Министерстве финансов РФ» и Федеральной службой по надзору в сфере связи, информационных технологий и массовых коммуникаций, является контроль за операциями подконтрольных агентов и отслеживание законности в организации расчетов $[4 ; 3$, с. 54].

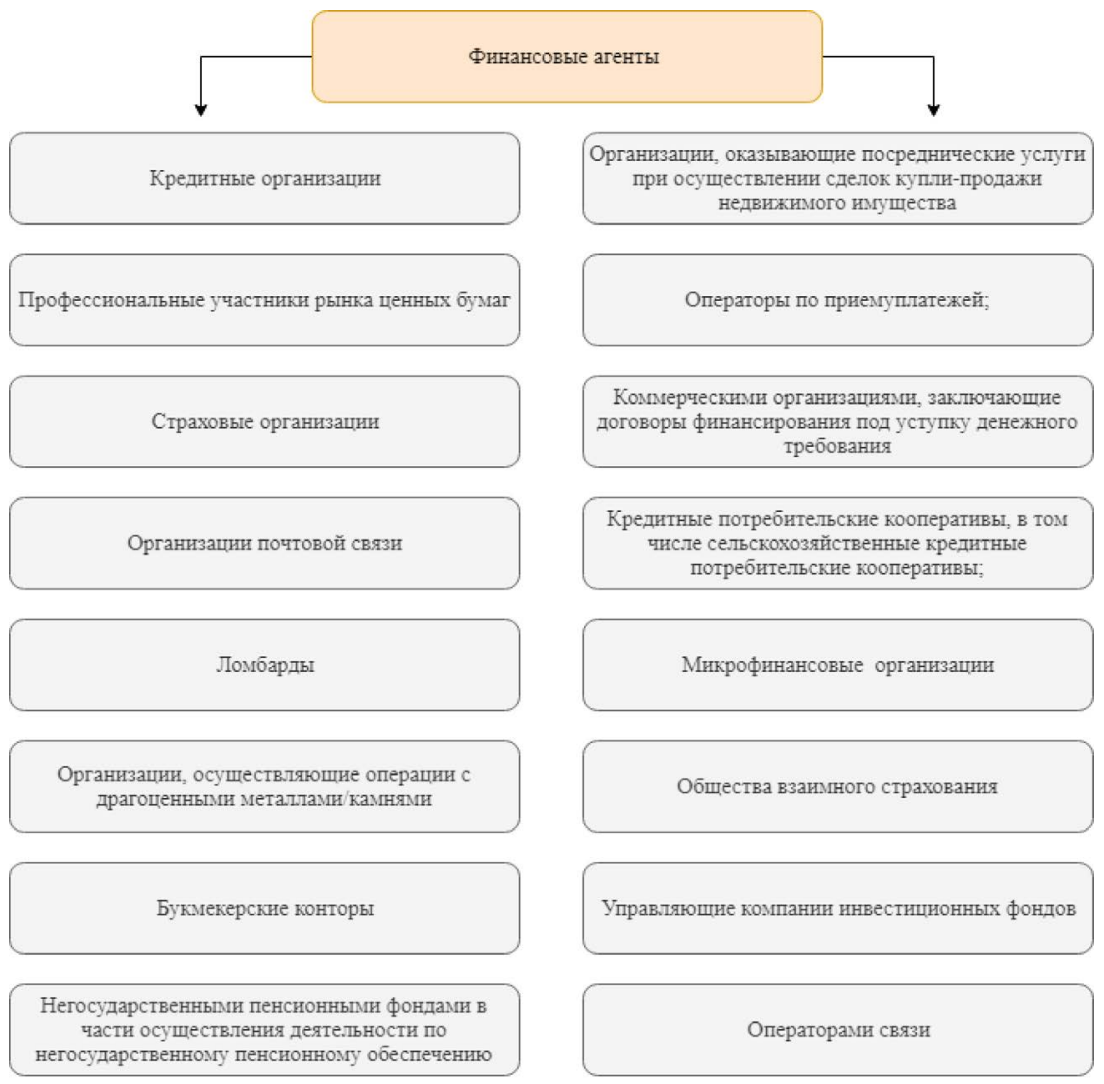

Рис. 3. Состав финансовых агентов в РФ 
Третий уровень системы мониторинга представлен агентами, финансовыми институтами, осуществляющими различные операции с денежными средствами и имуществом.

Эти структуры занимаются начальным сбором информации об всех операциях физических и юридических лиц, которые являются их клиентами, выгодоприобретателями или бенефициарами [7, c. $112 ; 8$, c. 10$]$.

Структура агентов в РФ представлена на рисунке 3.

Важно отметить, что сформировалась следующая организация надзорной деятельности государственных органов за финансовыми агентами, где каждому контрольному институту относится конкретный финансовый агент, который входит в сферу финансового мониторинга (рис. 4.)

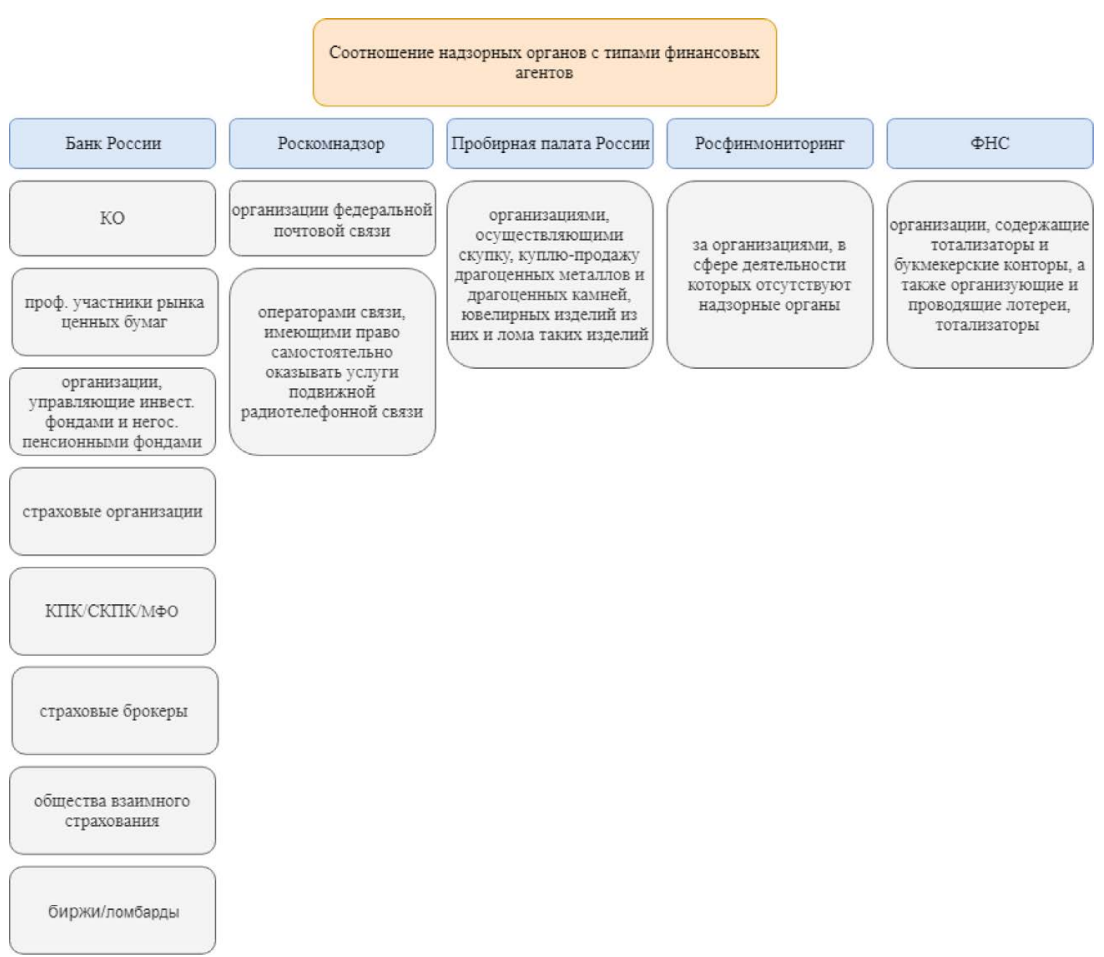

Рис. 4. Соотношение надзорных органов с типами финансовых агентов 
Можно выделить и четвертый уровень, представленный правоохранительными органами, которые непосредственно занимаются принятием информации по незаконной деятельности и ее пресечением. Но нужно отметить, в данном случае не совсем корректно относить правоохранительные органы к четвертому уровню, так как их деятельность регулируется уголовно-процессуальным правом, а рассмотренные выше - финансовым правом и соответствующими нормативно-правовыми актами [10].

О̄̄ъекты надзора, проводимого компетентными органами финансового мониторннга

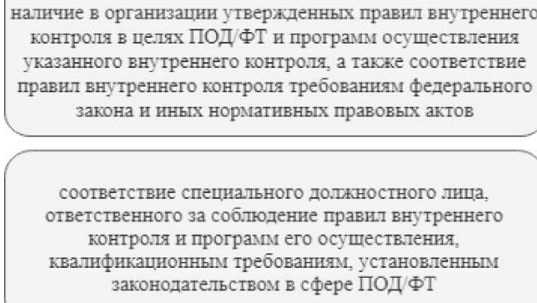
контроля в целях ПОД/ФТ и программ осуществления указанного внутреннего контроля, а также соответствие правнл внутреннего контроля требованиям федерального закона и иных нормативных правовых актов

соответствне спецнального должностного лнца, ответственного за соблюденне правил внутреннего контроля и программ его осуществления, квалифнкацнонным требованиям, установленным законодательством в сфере ПОД ФТ

собтодение органнзацией требований федерального закона и иных норматнвных правовых актов Российской Федерацин к подготовке и обученню кадров в сфере ПОД $\Phi \mathrm{T}$

соблюдение порядка документального фиксирования и направления в Росфинмониторинг сведений об̆ операциях с денежными средствами или нным нмуществом в случаях, установленных федеральным законом

соблюдение порядка хранення документов и информацни о6 операциях с денежными средствами или иным нмушеством в случаях, установленных федеральным законом налнине в организации уполномоченного сотрудника, ответственного за соблюдение правил внутреннего контроля и программ его осушествления, и документов о его назначенин

соблюдение организацией требований федерального закона и иных нормативных правовых актов Российской Федерации к подготовке и обучению кадров в сфере ПОД/ФТ

соблюдение порядка выявления операций, подлежащих обязательному контролю, и иных операций с денежными средствами или иным имуществом, в отношении которых в процессе осуществления внутреннего контроля возникают подозрения, что они осуществляются в целях ОД/ФТ

соблюдение требований по прностановлению операций $c$ денежными средствами нли нным имуществом в случаях, установленных федеральным законом

По фактам нарушений законодательства о ПОД/ФТ виновные лица привлекаются к административной ответственности по ст. 15.27 Кодекса Российской Федерации об административных правонарушениях

Рис. 5. Объекты финансового мониторинга

При этом объектами контроля выступают непосредственно сделки с денежными средствами, имуществом и правами на него. Объ- 
екты надзора, проводимого органами финансового мониторинга представлены на рисунке 5.

В связи с технологическим развитием, а также усилением угрозы терроризма система финансового мониторинга дополняется мерами контроля за распространением оружия и др. формами преступной деятельности, оставляющих «следы» у финансовых агентов [12, с. 32].

Однако, по нашему мнению, необходимо расширять систему мониторинга в связи с развитием ИКТ, создавать комплексную систему, охватывающую и электронные платежи через Интернет, особенно отслеживая так называемый «глубинный Интернет», через который проходит основные преступные денежные потоки - торговля людьми, оружием, наркотиками, биоресурсами и т.д. Особое внимание необходимо уделять криптовалютам и их применению в расчетах.

\section{Заключение}

Таким образом, мы можем сделать вывод, что на современном этапе нормальное развитие государства невозможно представить без финансовых отношений, которые в условиях усиления глобального экономического кризиса, организованного «финансового хаоса» и развития непубличных операций и расчетов за них с помощью ИКТ $[11$, c. 461]. Такое положение предполагает усиление регулирования и надзора со стороны государственных органов. При этом, для исполнения современного качественного контроля над финансами необходимо создание современного эффективного механизма, целью которого будет предупреждение, раскрытие и пресечения операций, относящихся к легализации незаконно полученных средств. В Российской Федерации по законодательству выстроена трехуровневая система финансового мониторинга. В соответствии с отпрядёнными законом функциями каждый уровень реализует свои задачи, основная из которых - охрана интересов и прав граждан, общества и государства.

\section{Список литературы}

1. Федеральный закон «О противодействии легализации (отмыванию) доходов, полученных преступным путем, и финансового терроризма» от 07.08.2001 №151-Ф3 (в редакции от 26.07.2019 №250-Ф3). 
2. Административный регламент Росфинмониторинга от 29.07.2014 № 191.

3. Букарев В.Б. Зарубежный опыт в сфере правового регулирования противодействия легализации (отмыванию) доходов, приобретенных преступным путем / В.Б. Букарев, Ю.В. Трунцевский, Н.А. Шулепов // Международное публичное и частное право. 2007. № 4. C. 54-59.

4. Егоров А.М., Егорова В.И. Финансовый мониторинг в России и его соотношение с правоохранительной деятельностью // Общество. Среда. Развитие (Terra Humana). 2007. №3. URL: https://cyberleninka. $\mathrm{ru} /$ article/n/finansovyy-monitoring-v-rossii-i-ego-sootnoshenie-spravoohranitelnoy-deyatelnostyu (дата обращения: 06.09.2019).

5. Едронова В.Н. Развитие системы финансового мониторинга в Российской Федерации // Национальные интересы: приоритеты и безопасность. 2016. №5 (338). С. 4-17.

6. Иманов Д.Э. Нормативно-правовые основы обеспечения национальной безопасности Российской Федерации на современном этапе // Наука Красноярья, 2017. Том 6, № 2. С. 61-79.

7. Морозов И.Л. Геополитическая безопасность современной России // Теория и практика общественного развития. 2015. № 8. С. 112-114.

8. Морозов И.Л. Новая стратегия национальной безопасности России и меняющийся мир // Общество: политика, экономика, право. 2016. № 4. C. 10-12.

9. Осипов А.В. Банковская система и финансовый мониторинг в РФ // Интерактивная наука. 2017. №4 (14). С. 184-186.

10.Пенчук А.В. Государственный финансовый контроль в Российской Федерации и направления его совершенствования // Концепт. 2014. №7. URL: https://e-koncept.ru/2014/14177.htm (дата обращения: 06.09.2019).

11. Хабриева Т.Я. Противодействие легализации (отмыванию) доходов, полученных преступным путем, и финансированию терроризма в условиях цифровизации экономики: стратегические задачи и правовые решения // Всероссийский криминологический журнал. 2018. T. 12. № 4. C. 459-467. 
12. Чиханчин Ю.А. Система финансовой безопасности Российской Федерации: концептуальные подходы и решения: научный доклад / под ред. академика РАН Т. Я. Хабриевой, канд. экон. наук Ю.А. Чиханчина. М.: Наука. 2015. 51 с.

13. Официальный сайт Федеральной службы по финансовому мониторингу. https://fedsfm.ru

\section{References}

1. Federal'nyy zakon «O protivodeystvii legalizatsii (otmyvaniyu) dokhodov, poluchennykh prestupnym putem, i finansirovaniyu terrorizma» ot 07.08.2001 N 115-FZ (v red. ot 26.07.2019 N 250-FZ) [Federal law "On counteracting the legalization (laundering) of criminally obtained incomes and financial terrorism" dated 08/07/2001 No. 151-FZ (as amended on July 26, 2019 No. 250-FZ)].

2. Administrativnyy reglament Rosfinmonitoringa ot 29.07.2014 № 191 [The administrative regulation of the Federal Financial Monitoring Service of July 29, 2014 No. 191].

3. Bukarev V.B., Truntsevskiy Yu.V., Shulepov N.A. Mezhdunarodnoe publichnoe i chastnoe pravo. 2007. № 4, pp. 54 -59.

4. Egorov A.M., Egorova V.I. Obshchestvo. Sreda. Razvitie (Terra Humana). 2007. №3. https://cyberleninka.ru/article/n/finansovyy-monitoring-v-rossii-i-ego-sootnoshenie-s-pravoohranitelnoy-deyatelnostyu

5. Edronova V.N. Natsional'nye interesy: prioritety i bezopasnost'. 2016. №5 (338), pp. 4-17.

6. Imanov D.E. Nauka Krasnoyar ’ya, 2017. Vol. 6, № 2, pp. 61-79.

7. Morozov I.L. Teoriya i praktika obshchestvennogo razvitiya. 2015. № 8, pp. 112-114.

8. Morozov I.L. Obshchestvo: politika, ekonomika, pravo. 2016. №4, pp. 10-12.

9. Osipov A.V. Interaktivnaya nauka. 2017. №4 (14), pp. 184-186.

10.Penchuk A.V. Kontsept. 2014. №7. https://e-koncept.ru/2014/14177.htm

11. Khabrieva T.Ya. Vserossiyskiy kriminologicheskiy zhurnal. 2018. V. 12. № 4, pp. 459-467.

12. Chikhanchin Yu.A. Sistema finansovoy bezopasnosti Rossiyskoy Federatsii: kontseptual'nye podkhody i resheniya: nauchnyy doklad [System of 
financial security of the Russian Federation: conceptual approaches and solutions: scientific report] / Ed. T.Ya. Khabrieva, Yu.A. Chikhanchin. M.: Nauka. 2015. 51 p.

13. Ofitsial'nyy sayt Federal'noy sluzhby po finansovomu monitoringu [The official website of the Federal Service for Financial Monitoring]. https:// fedsfm.ru

\section{ДАННЫЕ ОБ АВТОРАХ}

Сапожникова Светлана Михайловна, доцент кафедры экономики, кандидат экономических наук

Смоленский государственный университет

ул. Пржевальского 4, г. Смоленск, 214000, Российская Федеращчия

nrejkhert@yandex.ru

Рейхерт Наталья Владимировна, доцент кафедры экономики, кандидат экономических наук

Смоленский государственный университет

ул. Пржевальского 4, г. Смоленск, 214000, Российская Федеращия

\section{DATA ABOUT THE AUTHORS}

Sapozhnikova Svetlana Mikhailovna, Associate Professor, Department of Economics, Candidate of Economic Sciences

Smolensk State University

4, Przhevalsky str., Smolensk, 214000, Russian Federation nrejkhert@yandex.ru

ORCID: 0000-0002-1167-1999

Reichert Natalya Vladimirovna, Associate Professor, Department of Economics, Candidate of Economic Sciences

Smolensk State University

4, Przhevalsky str., Smolensk, 214000, Russian Federation ORCID: 0000-0002-7066-8466 